\title{
Low-frequency lower E-region wind and reflection height measurements as sensor for climate variability
}

\author{
C. Jacobi \\ Institute for Meteorology, University of Leipzig, Stephanstr. 3, 04103 Leipzig, Germany
}

\begin{abstract}
Measurements of reflection heights of lowfrequency (LF) radio waves at oblique incidence and estimates of mesosphere/lower thermosphere (MLT) region horizontal winds applying the D1 spaced receiver method on LF field strength registrations are analyzed with respect to possible long-term trends and interdecadal variability in the time interval from $\sim 1980$ to date. While no clear signal of mesospheric height trend is registered during the last two decades, significant trends of MLT horizontal winds are found. These trends are non-linear, in particular a change of trends around 1990 is found, which is probably connected with changes in tropospheric and stratospheric conditions at that time.
\end{abstract}

\section{Introduction}

Anthropogenic increase of greenhouse gases like $\mathrm{CO}_{2}$ results in a decrease of the middle atmosphere temperature (Lastovicka et al., 2006) owing to infrared emission. Cooling of the stratosphere has been reviewed by Ramaswamy et al. (2001), while Beig et al. (2003) and Beig (2006) have summarized the current knowledge on mesospheric cooling. They showed that this cooling amounts to about $2 \mathrm{~K} / \mathrm{dec}$ ade for the time interval from the 1960s to date. However, at that time no clear cooling trend is present in the mesopause region. The dynamics and variability of the mesosphere/lower thermosphere (MLT) on the other hand is of particular interest, since it is steered both by the general radiatively driven middle atmosphere circulation and dynamical influences through wave propagation from below.

Recent analyses using results of long-term low-frequency (LF) radio wave reflection height measurements have shown that mesospheric cooling is not linear. In particular, a corre-

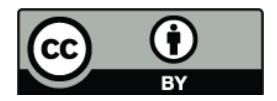

Correspondence to: C. Jacobi (jacobi@uni-leipzig.de) lation is found between mesospheric temperatures and stratospheric ozone (Bremer et al., 2005), which plays a major role in the middle atmosphere energetics. Changes in temperature affect the wind field. Recent results on long-term changes in MLT winds have been published by Jacobi and Kürschner (2006) and Portnyagin et al. (2006). They showed that MLT wind parameters have significantly changed since the beginning of the early 1960s. The sign of the linear trends, however, seems to change in the early 1990 s, which qualitatively agrees with the behavior of mesospheric temperatures.

To summarize, there are still open questions on the nature of MLT trends and its possible connection with climate change. In the following, measurements of winds and reflection heights using low frequency (LF) radio waves are presented to contribute to the database available for mesospheric trend analysis.

\section{LF measurements at Collm Observatory}

At Collm Observatory $\left(51.3^{\circ} \mathrm{N}, 13.0^{\circ} \mathrm{E}\right)$, MLT winds are measured by D1 LF radio wind measurements, using the ionospherically reflected sky wave of three commercial radio transmitters. The data are combined to half-hourly zonal and meridional mean wind values. A multiple regression analysis is used to determine the daily prevailing wind and the semidiurnal tidal wind components assuming clockwise circularly polarized tidal wind components (Kürschner, 1991; Jacobi et al., 1998). The same method is applied to calculated monthly wind parameters using monthly median halfhourly winds (Jacobi and Kürschner, 2006). The data are attributed to the mean reflection height at about $90 \mathrm{~km}$. Results of wind measurements are used only since 1979 to avoid inhomogeneity of the time series due to modifications in the data analysis procedure in 1978.

The time series of daily prevailing winds include, besides the seasonal variation, much variability on the day-to-day

Published by Copernicus Publications on behalf of the URSI Landesausschuss in der Bundesrepublik Deutschland e.V. 


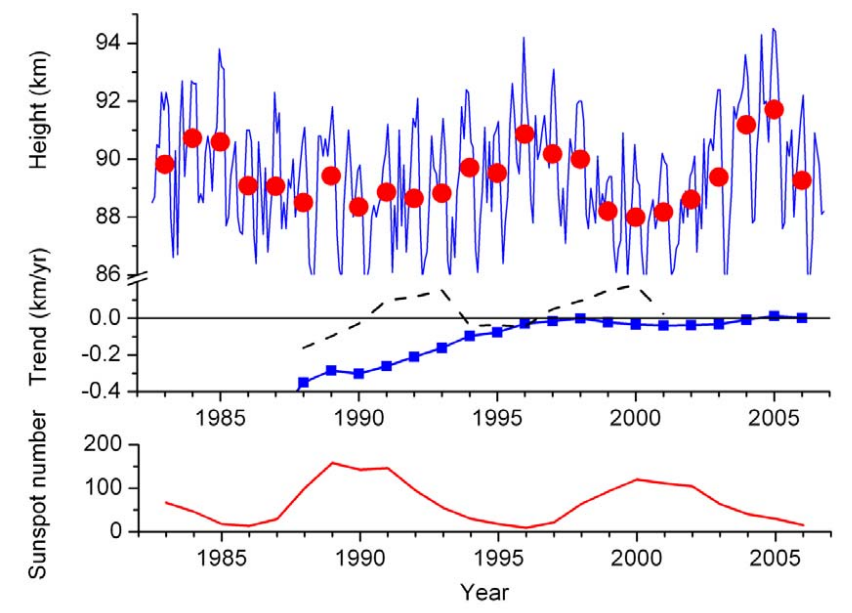

Fig. 1. Upper panel: Time series of monthly mean nighttime (21:00-01:- UT) reflection heights (blue line), together with annual mean values (red dots). In the lower part the trend coefficients are added (a) for different analyses covering the time interval from 1983 to the respective year (blue line + squares), and (b) for a 11-year window centered at the respective year(black dashed line). Lower panel: Annual mean sunspot number.

time scale. This may partly be due to uncertainties in the daily wind analysis and a possible impact of mean nighttime height changes from day to day. The major part of this variability, however, is owing to planetary waves (PWs). To investigate this, a Lanczos filter with 100 weights is applied to the time series of daily zonal and meridional prevailing winds in order to analyse the variability of the wind field in a period band of 2-30 days. From these filtered time series daily values of the standard deviation $\sigma$ are calculated using a 48-day time interval each, while the respective value is attributed to the centre of the interval. From these data annual means are calculated. The procedure is similar to that applied in Jacobi et al. (1998).

The virtual reflection heights $h^{\prime}$, referring to the reflection point at $52.1^{\circ} \mathrm{N}, 13.2^{\circ} \mathrm{E}$, are estimated since late 1982 using measured travel time differences between the separately received ionospherically reflected sky wave (transmitter Zehlendorf, $177 \mathrm{kHz}$, distance to receiver $\sim 165 \mathrm{~km}$ ) and the ground wave through phase comparisons between both components on sporadic oscillation bursts of LF radio waves in a small modulation frequency range around $1.8 \mathrm{kHz}$ (Kürschner et al., 1987). Half-hourly virtual reflection heights range between $h^{\prime}=80 \mathrm{~km}$ during daytime and $h^{\prime} \geq 100 \mathrm{~km}$ during nighttime. Owing to the effect of electromagnetic waves group retardation the measured virtual heights $h^{\prime}$ are larger than the real heights $h$, the difference amounts to several $\mathrm{km}$, increasing with altitude.
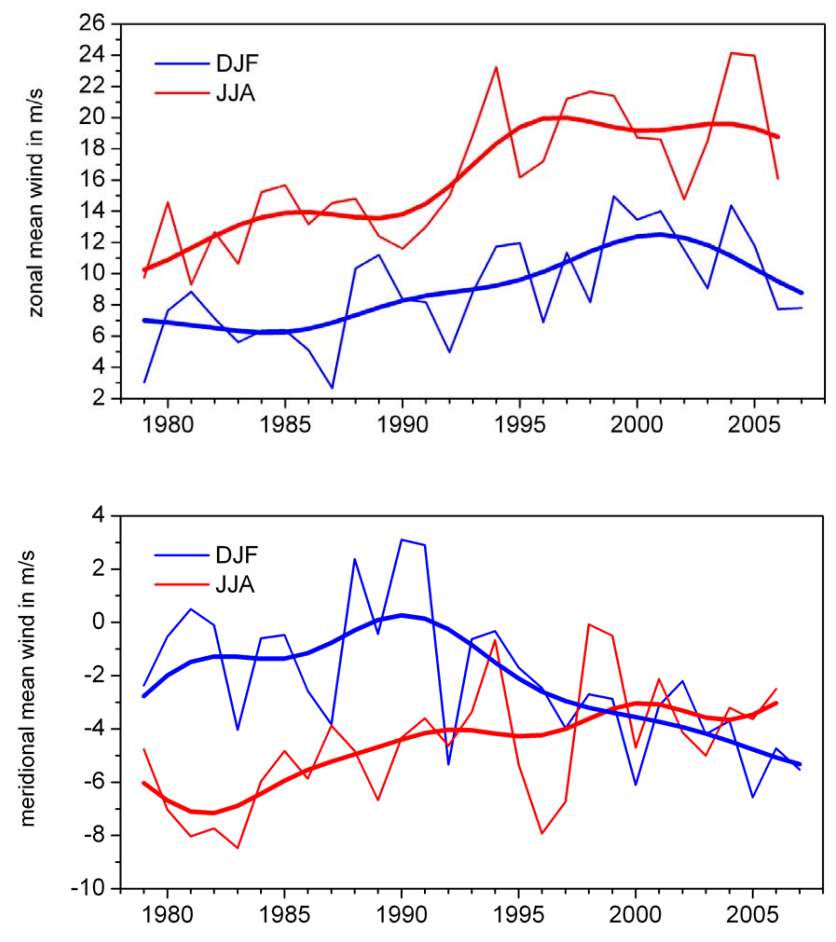

Fig. 2. Time series of December-February (DJF, blue, the year refers to the one of the respective January) and June-August (JJA, red) mean zonal (upper panel) and meridional (lower panel) prevailing winds over Collm. The smoothed lines were constructed using a 5-pt FFT filter.

\section{The signal of mesospheric temperature in the LF re- flection heights}

The change of the daily mean reflection heights on time scales of years to decades can be interpreted as an effect of temperature changes of the middle atmosphere below (Bremer and Berger, 2002; Kürschner and Jacobi, 2003; Bremer et al., 2005). Since cooling of the middle atmosphere leads to a shrinking of atmospheric layers, this is connected with a decrease of the height of constant electron density and this causes a decrease of the reflection heights of LF radio waves. However, Bremer et al. (2005) showed that in the course of the 1990s the mesospheric cooling trend vanishes (and even reverses), which may be connected with the stratospheric ozone recovery during the last decade.

Reflection heights measured at Collm are presented in Fig. 1. The data have been corrected for group retardation using an empirical polynomic function based on comparisons between LF and meteor radar winds both measured at Collm. In the lower part of the upper panel the long-term trends are shown, each calculated to the respective year. One can see that the negative trend, which is present until the mid 1990 decreases, so that on the whole no trend between 1983 and 2007 is visible. Kürschner and Jacobi (2003) have reported a negative trend between 1983 and 2001, so that this shows 
Table 1. Long-term linear trend parameters for zonal $\left(v_{o z}\right)$ and meridional $\left(v_{o m}\right)$ prevailing winds over Collm.

\begin{tabular}{ccccc}
\hline Parameter & $\begin{array}{c}\text { Trend/DJF } \\
(1979-2007)\end{array}$ & Correlation coefficient & $\begin{array}{c}\text { Trend/JJA } \\
(1979-2006)\end{array}$ & Correlation coefficient \\
\hline$v_{o z}$ & $+0.23 \mathrm{~ms}^{-1} / \mathrm{yr}$ & 0.59 & $+0.38 \mathrm{~ms}^{-1} / \mathrm{yr}$ & 0.74 \\
$v_{o m}$ & $-0.17 \mathrm{~ms}^{-1} / \mathrm{yr}$ & 0.56 & $+0.15 \mathrm{~ms}^{-1 / y r}$ & 0.56 \\
\hline
\end{tabular}

the increasing reflection heights since 2001, which have also been reported by Bremer et al. (2005). Calculating trends using an 11-year window shows that after 1990 on average no negative, but rather a weak positive trend is observed.

\section{Mesopause region winds and waves}

Seasonal mean values of MLT zonal and meridional winds over Collm are shown in Fig. 2. The data represent an update from Jacobi and Kürschner (2006). Positive values denote eastward zonal or northward meridional winds, respectively. Linear trend coefficients are provided in Table 1. One can see that winds change significantly during the time interval considered. The zonal wind increases both in summer and winter, while the meridional wind decreases in summer (note that the winds are negative, i.e. a decrease is represented by a positive trend), while in winter the winds behave in a more complicated manner, although the overall long-term trend is negative, and significant at the $99 \%$ level.

A closer look, however, shows that these trends are obviously not linear, and have changed during the 1990s. As an example, in Fig. 3 linear trends are presented for the zonal and meridional prevailing winds that have been calculated from a running 13-year window. While in the 1980s there is no trend of the zonal prevailing wind, it increases since the late 1980s/early 1990s, and remains at a quasi-constant level since the late 1990s. This means that there was a more stepwise change of MLT winds around 1990, but no large trends before or after that time. Meridional winds behave somewhat different. In summer the northward (negative) winds more or less continuously decrease, i.e. the trends are positive. Since meridional winds in summer are forced by atmospheric gravity waves, this indicates a change in gravity wave filtering in the middle atmosphere and may be explained by a greenhouse gas and ozone change response of the mesosphere (Jacobi et al., 2003). The decrease seems to level off in the course of the time interval considered, which is, however, not necessarily an indication of reduced middle atmosphere forcing, but owing to the fact that the residual circulation may decrease in strength, but not change sign. In winter, PW influence the middle atmosphere circulation, so that changes of tropospheric parameters may affect the MLT circulation. The weak or slightly positive trends until 1990 are followed by negative trends later. This means that there
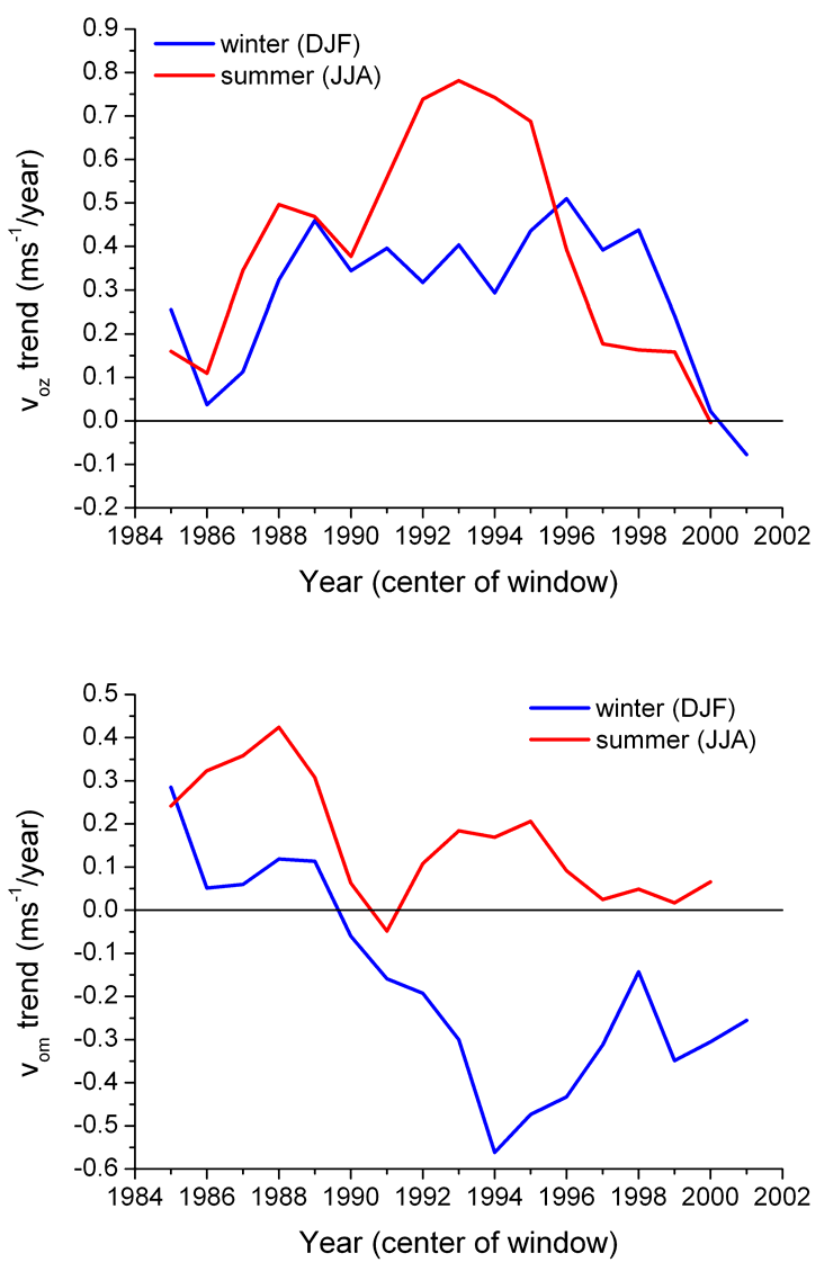

Fig. 3. Linear trends for DJF and JJA mean zonal (upper panel) and meridional (lower panel) prevailing winds from Fig. 2, calculated using 13-year running windows centered at the respective years.

is again a change in the circulation around 1990 as is the case with the zonal prevailing winds. This change is probably owing to tropospheric circulation changes. In Fig. 4 time series of the North Atlantic Oscillation (NAO) index are presented. The NAO is the dominant circulation pattern in the European-Atlantic sector, and strongly influences European climate in winter. Since this is connected with PW activity, the MLT circulation is also forced by the NAO in winter (Jacobi and Beckmann, 1999). 


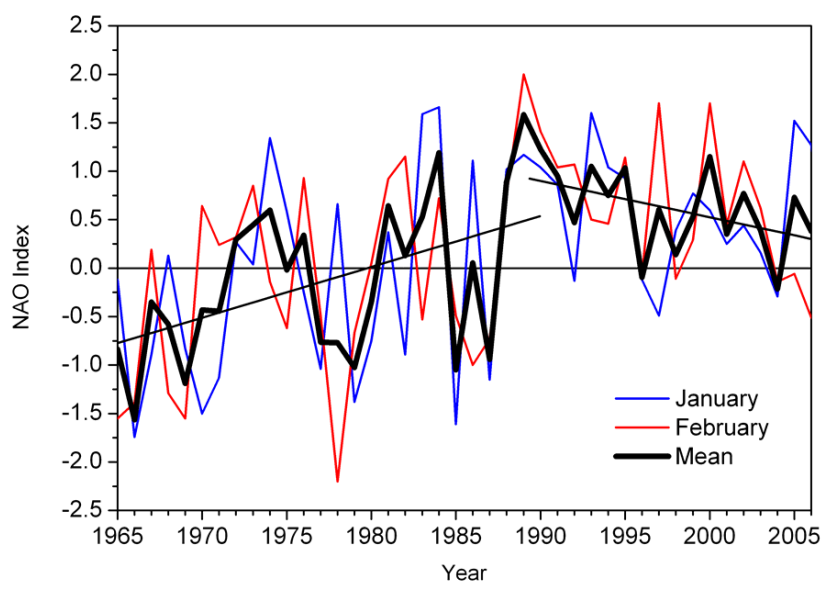

Fig. 4. Time series of monthly mean NAO indices for two winter months.

Annual mean values of the zonal and meridional wind standard deviation, being a proxy for PW activity in the MLT in the period range 2-30 days, are shown in Fig. 5. Obviously, there is considerable interannual and interdecadal variability of both parameters. In particular, the difference between the zonal and the meridional component is small in the early years, but increases to a value of about $3 \mathrm{~m} / \mathrm{s}$ since about 1990. This is the result of a positive trend of the zonal component, but a negative trend of the meridional one. These trends are superposed by large are more or less irregular variations at time scales of years to even decades. The difference between the components, however, indicates a more stepwise increase around 1990.

\section{Conclusions}

Temperature proxies measured over Collm indicate that a substantial change has occurred in the MLT around 1990. This coincides with results by Bremer et al. (2005) who measured nearly no reflection height trend after the early 1990s. They showed this trend in connection with the recovery of the ozone layer taking place since the early 1990s. In contrast, Remsberg and Deaver (2005) reported negative trends for the subtropical mesosphere from HALOE data 1991-2004. However, satellite mesospheric data (their Fig. 1) also show an increase of temperature after 1990, which, however, may as well be due to the 11-year solar cycle.

Collm LF measurements show that, coinciding with the long-term behavior of temperatures, the MLT winds, and especially PWs, have substantially changed around 1990. This substantiates the hypothesis, that the upper middle atmosphere long-term trends are not only due to greenhouse gas changes, but rather are the result of several influences. It seems that the ozone change possibly plays a role in the temperature changes of the middle atmosphere. Other possi-

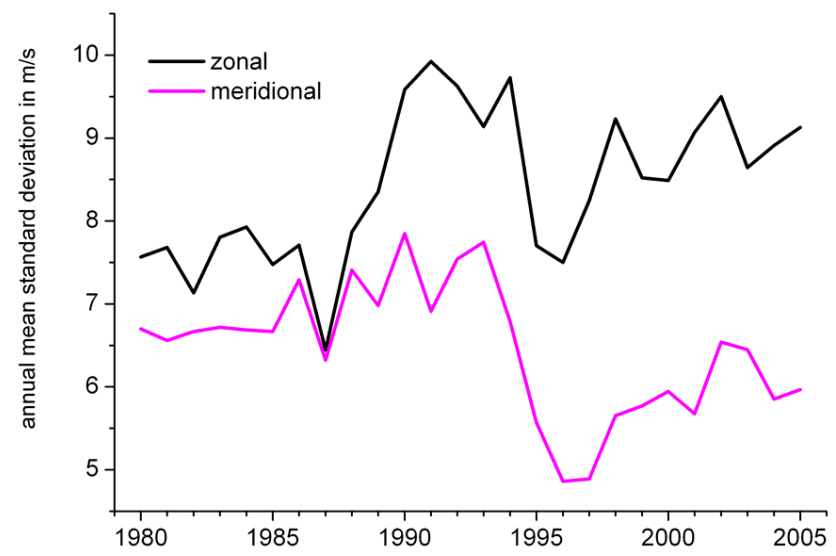

Fig. 5. Time series of annual mean zonal and meridional standard deviation, calculated from daily wind analyses near $90 \mathrm{~km}$, and filtered in the period range 2-30 days.

ble mechanisms influencing the MLT circulation involve tropospheric circulation changes, e.g. expressed through variations of the North Atlantic Oscillation, which also exhibited an increase in the 1990s.

Acknowledgements. This study was supported by Deutsche Forschungsgemeinschaft under JA 836/22-1. NAO indices have been provided by NWS/NOAA/CPC through their web site on http://www.cpc.ncep.noaa.gov/products/precip/CWlink/pna/ nao_index.html. Sunspot numbers have been provided by NOAA/NGDC Solar-Terrestrial Physics Division through their Web site on http://www.ngdc.noaa.gov/stp/stp.html.

\section{References}

Beig, G.: Trends in the mesopause region temperature and our present understanding - an update, Phys. Chem. Earth, 31, 3-9, 2006.

Beig, G., Keckhut, P., Lowe, R. P., Roble, R. G., Mlynczak, M. G., Scheer, J., Fomichev, V. I., Offermann, D., French, W .J. R., Shepherd, M. G., Semenov, A. I., Remsberg, E. E., She, C. Y., Lübken, F.-J., Bremer, J., Clemesha, B. R., Stegman, J., Sigernes, F., and Fadnavis, S.: Review of mesospheric temperature trends, Rev. Geophys., 41, 1015, doi:10.1029/2002RG000121, 2003.

Bremer, J. and Berger, U.: Mesospheric temperature trends derived from ground-based LF phase-height observations at midlatitudes: comparison with model simulations, J. Atmos. SolarTerr. Phys., 64, 805-816, 2002.

Bremer, J., Schacht, J., and Barth, Th.: Einfluss von Ozonvariationen auf Trends in der Mesosphäre mittlerer Breiten. LeibnitzInstitut für Atmosphärenphysik e.V. an der Universität Rostock, Institute Report 2004/2005, 94-95, 2005.

Jacobi, Ch., Schminder, R., and Kürschner, D.: Planetary wave activity obtained from long-term (2-18 days) variations of mesopause region winds over Central Europe $\left(52^{\circ} \mathrm{N}, 15^{\circ} \mathrm{E}\right), \mathrm{J}$. Atmos. Solar-Terr. Phys., 60, 81-93, 1998.

Jacobi, Ch. and Beckmann, B.-R.: On the connection between upper atmospheric dynamics and tropospheric parameters: corre- 
lation between mesopause region winds and the North Atlantic Oscillation, Clim. Change, 43, 629-643, 1999.

Jacobi, Ch., Lange, M., and Kürschner, D.: Influence of anthropogenic climate gas changes on the summer mesospheric/lower thermospheric meridional wind, Meteorol. Z., N.F. 12, 37-42, 2003.

Jacobi, Ch. and Kürschner, D.: Long-term trends of MLT region winds over Central Europe, Phys. Chem. Earth, 31, 16-21, 2006.

Kürschner D.: Ein Beitrag zur statistischen Analyse hochatmosphärischer Winddaten aus bodengebundenen Messungen, Z. Meteorol., 41, 262-266, 1991.

Kürschner, D., Schminder, R., Singer, W., and Bremer, J.: Ein neues Verfahren zur Realisierung absoluter Reflexionshöhenmessungen an Raumwellen amplitudenmodulierter Rundfunksender bei Schrägeinfall im Langwellenbereich als Hilfsmittel zur Ableitung von Windprofilen in der oberen Mesopausenregion, Z. Meteorol., 37, 322-332, 1987.

Kürschner, D. and Jacobi, Ch.: Quasi-biennial and decadal variability obtained from long-term measurements of nighttime radio wave reflection heights over central Europe, Adv. Space Res., 32, 1701-1706, doi:10.1016/S0273-1177(03)00773-2, 2003.
Lastovicka, J., Akmaev, R. A., Beig, G., Bremer, J., and Emmert, J. T.: Global change in the upper atmosphere, Science, 314, 12531254, 2006.

Portnyagin, Yu. I., Merzlyakov, E. G., Solovjova, T. V., Jacobi, Ch., Kürschner, D., Manson, A., and Meek, C.: Long-term trends and year-to-year variability of mid-latitude mesosphere/lower thermosphere winds, J. Atmos. Solar-Terr. Phys., 68, 1890-1901, 2006.

Ramaswamy, V., Chanin, M.-L. , Angell, J., Barnett, J., Gaffen, D., Gelman, M., Keckhut, P., Koshelkov, Y., Labitzke, K. , Lin, J.J.R., O’Neill, A., Nash, J., Randel, W., Rood, R., Shine, K., Shiotani, M., and Swinbank, R.: Stratospheric temperature trends: Observations and model simulations, Rev. Geophys., 39, 71-122, 2001.

Remsberg, E. E. and Deaver, L. E.: Interannual, solar cycle, and trend terms in middle atmospheric temperature time series from HALOE, J. Geophys. Res., 110, D06106, doi:10.1029/2004JD004905, 2005. 